\title{
Correction to: Product Delivery and Simulation for Industry 4.0
}

Oliverio Cruz-Mejía, Alberto Márquez

and Mario M. Monsreal-Barrera

\section{Correction to:}

Chapter "Product Delivery and Simulation for Industry

4.0" in M. M. Gunal (ed.), Simulation for Industry 4.0, Springer Series in Advanced Manufacturing, https://doi.org/10.1007/978-3-030-04137-3_5

In the original version of the book, the co-author's misspellt name "Monsreal-Berrera" has been changed to read as "Monsreal-Barrera" in Chapter " 5 ".

The erratum chapter have been updated with the change. 